\title{
DECOLONIALIDADE \& SOCIOLOGIA NA AMÉRICA LATINA
}

Resenha de: CASTRO, Edna; PINTO, Renan Freitas (organizadores). Decolonialidade e Sociologia na América Latina. Belém: NAEA, 2018. 394p.

\section{Pedro Henryque Paes Loureiro de Bragança ${ }^{1}$}

http://orcid.org/0000-0003-2910-2871 http://lattes.cnpq.br/4225735361300951

Recebido em: 17 de março de 2020

Aprovado em: 29 de junho de 2020

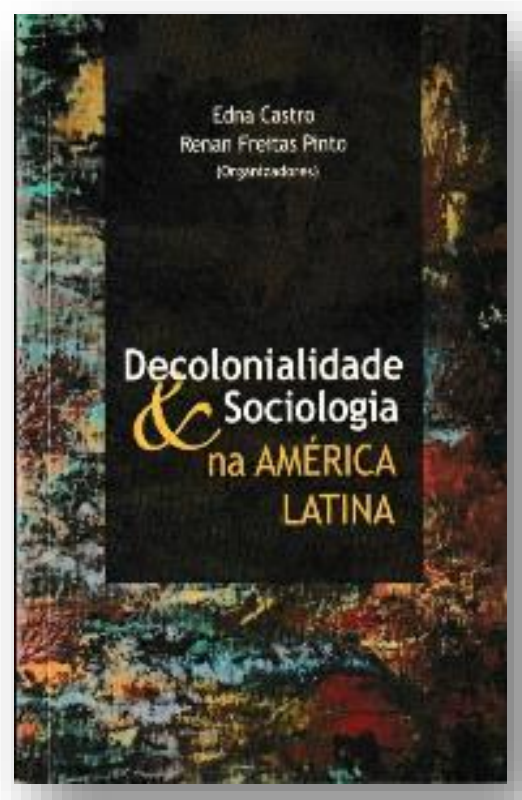

Decolonialidade \& Sociologia da América Latina, organizado por Edna Castro e Renan Freitas Pinto (2018) apresenta uma contribuição ao debate sobre a decolonialidade do saber e do poder na America Latina, em especial sobre o pensamento social latino-americano na perspectiva de um programa amplo de investigação sobre a modernidade ocidental, a colonialidade e a decolonialidade. $\mathrm{O}$ desafio central é a análise das sociedades latino-americanas, sua história colonial ligada, à escravidão e a reprodução das estruturas do pensamento e do imaginário colonial na contemporaneidade.

A coletânea resulta de um projeto construído ao longo de dois anos no exercício da Disciplina Teoria Sociológica III/Sociologia da América Latina, do Programa de Pósgraduação em Sociologia e Antropologia (PPGSA), da UFPA, sob responsabilidade da Professora Edna Castro e tendo a participação do Professor Renan Freitas Pinto, da Universidade Federal do Amazonas, e dos professores Edila Moura e Rodrigo Peixoto, do PPGSA.

Contém 14 artigos de docentes, discentes e de autores convidados com variadas abordagens acerca da formação e da institucionalização do pensamento sociológico no continente americano como um exercício de pensar a sociologia a partir do lugar social, de suas realidades vividas e de onde emerge um fértil campo da crítica ao conhecimento com a intenção de tornar visível epistemologias sobre a construção do que os autores chamam de "inversão do olhar" e nos coloca diante de um mosaico de formações de pensamento que permeiam a construção

${ }^{1}$ Bacharel em Direito e em Comunicação Social com habilitação em Jornalismo; Especialista em Jornalismo, Cidadania e Políticas Públicas; Mestre em Planejamento do Desenvolvimento e Doutorando em Ciências: Desenvolvimento Socioambiental, no Programa de Pós Graduação em Desenvolvimento Sustentável do Trópico Úmido, do Núcleo de Altos Estudos Amazônicos, da Universidade Federal do Pará (PPGDSTU/NAEA/UFPA). E-mail: pedrohloureiro@gmail. com. 
sociológica da América Latina e as suas peculiaridades, nos oferecendo a oportunidade de aproximar de realidades que embora sejam tão próximas da nossa, são colocadas como distantes pelas barreiras hegemônicas que o pensamento eurocêntrico impõe.

O trabalho da Sociologia, como referido neste livro, corresponde à desconstrução de matrizes teóricas que estruturam as narrativas sociológicas clássicas ocidentais. O colonialismo interno e os estudos decoloniais tem produzido reflexões importantes que se aproximam a teses caras aos movimentos sociais e étnicos que atravessam a história de lutas, de resistências e de construções emancipatórias na América Latina.

Os capítulos são conectados pela reflexão acerca da realidade latino-americana, a partir de uma perspectiva crítica, que produz leituras sobre autores e obras que adotaram essa perspectiva e tem contribuído na construção de um pensamento que reage à tradição eurocêntrica da Sociologia, produzindo, também, um distanciamento da ciência ocidental que construiu seu sistema teórico de conhecimento, base da formação da Sociologia e das demais ciências sociais.

$\mathrm{O}$ artigo Epistemologias do Sul e caminhos da crítica sociológica contemporânea, de Edna Castro, abre as discussões do livro com possibilidades de abordagens objetivando compreender a pluralidade epistemológica em diversos contextos sociais, étnicos e políticos, produzindo uma aproximação metodológica a partir da prática de pesquisa e da experiência de pesquisa-ação-política. De acordo com a autora, a diversidade de conhecimento do mundo que não é identificada nas grandes correntes do pensamento moderno ocidental, da filosofia grega à ciência moderna, e à modernidade, é vista por Boaventura dos Santos como "epistemologias do sul" (2012) e os autores filiados a esta corrente buscam imaginar uma perspectiva crítica à epistemologia moderna, visando romper com o evolucionismo e alterar as narrativas dominantes na medida que reconhece que o saber é parte da práxis e da experiência coletiva.

A autora, que também é uma das organizadoras da coletânea, debate o campo científico como um lugar de lutas simbólicas na afirmação da sociologia latino-americana, em especial na lacuna de conhecimento na sociologia brasileira acerca da produção intelectual na América Latina, discute o conceito de desenvolvimento como um enunciado de dominação colonial e a resistência crítica de autores nessa inversão do olhar; aborda as consequências da modernidade e do progresso na hegemonia da razão e a superestimação do conhecimento científico em relação a outras formas de conhecimento; e discute o capitalismo, o aumento da desigualdade e a formação de zonas de sacrifício em territórios sociais e étnicos.

$\mathrm{Na}$ sequência, Sirlei Silveira aborda em América: projeção da geografia fantástica das Índias como as Grandes Navegações foram influenciadas por visões míticas e narrativas prodigiosas acerca do Oriente e como estas imagens até certo ponto utópicas sobre as terras e gentes asiáticas não permitiu a "descoberta" cognitiva da América pelos ibéricos como um continente munido de características próprias. Embora o encontro com essas terras e gentes pudesse ser um fato novo, ele foi interpretado a partir de imagens e valores os supostos descobridores já traziam consigo, onde reinava a ideia de um lugar próspero onde os sonhos se realizariam. Seus olhos viam apenas o queriam ver e encontraram somente o que queriam encontrar, encobrindo outras realidades em virtudes de suas próprias projeções sobre as Índias Orientais.

Em Octavio Ianni e a "redescoberta" da América Latina, Renan Freitas Pinto, faz um pequeno ensaio acerca das ideias do professor Octávio Ianni sobre o continente americano face ao imperialismo e a pretensão de hegemonia dos Estados Unidos sobre seus países. Com uma abordagem complexa e multidisciplinar dos problemas da América Latina, valoriza o peso da condição colonial e escravistas em suas origens e permanências, bem como compreende que 
foram estabelecidas formas de governo marcadas pela geopolítica do imperialismo estadunidense, convertendo a região em sua área preferencial de influência e controle, proporcionando terreno fértil para experimentações autoritárias.

Em Novas fronteiras de grãos e desmatamento na Amazônia, Carlos Potiara Castro, examina dinâmicas socioeconômicas na rodovia BR-163, a Cuiabá-Santarém, para tentar entender as ações e as estratégias sociais dos atores que estão presentes na fronteira, em especial sua relação com o território, as estratégias de apropriação dos recursos naturais e a sucessão de atores sociais na ocupação da terra caracterizando um novo momento de expansão do mercado, de conflitos e ampliação do desmatamento.

$\mathrm{O}$ artigo Colonialidade do poder: conceito e situações e decolonialidade no contexto atual, de Rodrigo Peixoto e Kércia Figueiredo, aborda a contribuição dos autores Peruanos Anibal Quijano e Carlos Mariátegui para abordar a ideia de raça como "um poderoso construto ideológico que opera como instrumento de dominação” (p. 127), sendo, junto com gênero e classes sociais, estruturantes na distribuição de poder entre as pessoas. A partir deste conceito, o artigo demonstra situações de colonialidades e decolonialidades no contexto político brasileiro de 2019 e do movimento indígena do baixo Tapajós. Quijano explicita a desigualdade das relações humanas e destes com a natureza, assim como propõe caminhos para a superação, como fazendo referência à filosofia do Bem Viver, adotada por povos originários e que se opõe ao discurso desenvolvimentista da exploração predatória de recursos naturais em prol da satisfação material e individual a qualquer custo.

Brenda Thainá Cardoso de Castro analisa o outro lado da fronteira em Sociologia colombiana: trajetória e fundações no pensamento de Fals Bordas e Camilo Torres, onde esquematiza a trajetória sociológica da Colômbia a partir da contribuição de dois de seus fundadores: Camilo Torres Restrepo e Orlando Fals Borda, que aborda a história e institucionalização da sociologia no país, dando ênfase numa revisão de literatura destes autores. "A política, a pesquisa, a guerrilha e os projetos de investigação” (p. 187) marcaram a trajetória de ambos, que se tornaram referência para compreensão dos fenômenos sociais do país, no qual a questão política (violência, luta pelo campo e guerrilhas) deu o tom diversas vezes ao percurso da Sociologia, que também pautou a própria política, embora os efeitos só de tornem perceptíveis em longo prazo.

Silvio Kanner Pereira Farias, Gilson da Silva Costa e Elineuza Alves da Silva, em Colonialidade e eurocentrismo: "carreteras" para um estudo da história da sociologia no Peru elaboraram uma revisão crítica do processo histórico peruano a partir de autores-chave de diferentes momentos, dividindo-o artigo em três seções: Primeiro um estudo dos fundadores do pensamento social peruano e sua relação com o pensamento pós-colonial, como Francisco Calderón, Haya de La Torre e José Carlos Mariátegui; Depois as duas correntes mais importantes da sociologia peruana: de um lado a estrutural-funcionalista, inspirada em François Bourricard e de outro a tentativa de construção de uma sociologia crítica peruana de Anibal Quijano, inicialmente marxista, todavia fundamentais na formulação da perspectiva pós-colonial. $\mathrm{Na}$ derradeira etapa são apontadas as semelhanças entre o trabalho de Quijano com o de Mariátegui, como a questão da superação da herança colonial, pois considerava que a existência da cultura Inca constituía uma realidade que não poderia ser pensada a partir de categorias clássicas do marxismo. A crítica ao evolucionismo e ao eurocentrismo e a valorização da cultura Inca, foram fundamentais para o desenvolvimento posterior da perspectiva de pensamento pós-colonial.

Pensamento social boliviano: práticas descoloniais indígenas e conflitos políticos, de João Luiz da Silva Lopes, discute a produção sociológica na Bolívia com uma retrospectiva da construção do 
pensamento social a partir da dualidade entre o processo de institucionalização da Sociologia e a existência de um pensamento paralelo ao acadêmico, chamado de Pensamento Indianista, baseado no universo ou cosmologia indígena com base na periodização realizada por Santos e Baumgarten (2005), atualizando o debate com os principais conflitos teóricos e práticos acerca do período chamado de Sociologia da descolonização. O artigo constata que, em relação à questão indígena, a perspectiva da integração e da homogeneização cultural, tanto na política como na ciência social ainda é presente no pensamento social hegemônico, reproduzindo pensamento e práticas coloniais. O autor aponta a necessidade de reconhecimento e atuação a partir de epistemes e éticas alternativas que possibilitem a busca de outros horizontes "livres da homogeneização, da dicotomização, da centralização, da dominação, resumindo, da colonização" (p. 232) e conclui que o fracasso da experiência índia com o poder reforça a "necessidade de atuar no processo de descolonização a partir de outras epistemes e cosmologias" (p. 232).

O texto Imagem, arte e práticas descolonizadoras: contribuiçoes e possibilidades de pensar a América Latina pelo cinema e o audiovisual (Bolivia e Brasil), de Valber Oliveira de Brito e Jorge Oscar Santos Miranda, faz uma análise acerca do cinema e audiovisual levando em consideração os aspectos ideológicos, éticos e problemas comportamentais decorrentes, a partir de uma breve leitura sobre os principais diretores e cineastas latino-americanos cujas expressões artísticas estejam próximas do pensamento decolonial e pós-colonial, trazendo como diferencial a inclusão da autora Silvia Rivera Cusicanqui, dedicando-se a discutir sobre as contribuições de seu pensamento e da concepção de imagem que fundamentam o seu cinema e produção audiovisual, em diálogo com a realidade amazônica, em duas produções Marias da Castanha (1987) e Fronteira Carajás (1992), da pesquisadora Edna Castro, onde "realiza uma leitura visual considerando múltiplas dimensões do imaginário e da experiência, que envolve imagens, gênero, trabalho, lugar e ações coletivas” (p. 239), categorias de análise constantes em suas pesquisas direcionadas à interpretação da realidade amazônica.

Descendo ao rio da Prata, Marcelo Santos Sodré escreve sobre O pensamento social na Argentina: reflexões sociológicas do colonialismo e do pós-colonialismo, fazendo uma análise histórica da sociologia argentina desde 1850, destacando os principais pensadores me meio às transformações na conjuntura social, política e econômica do país, evidenciados em dois momentos distintos: entre 1850 a 1950 predominou o pensamento colonial e a germinação do pensamento crítico ou post colonial, que a partir da segunda metade do século XX passou a disputar espaço com o pensamento colonial nas universidades e por toda América Latina. O autor também considera a consolidação da sociologia como carreira, na década de 1970, foi importante para a ampliação destes debates e para compreensão dos acontecimentos locais e regionais no continente, como as discussões de autores como Walter Mignolo, Enrique Dussel e Maristela Svampa, que foram as principais referências do artigo.

Glaucia Macedo Sousa se debruça na obra de Héctor Moreno para conduzir o capítulo Ciências Sociais e teoria da colonialidade no Chile: contribuições de Héctor Nabuelpán Moreno e associa as problemáticas tratadas por ele com sua origem Mapuche, permeada por negações, invisibilidades e silêncios paradigmáticos sobre o passado e o presente indígena que corresponde a processos de negação do direito à diferença, e à exclusão epistêmica do direito. Apesar de sua formação universitária tenha sido dirigida para uma perspectiva colonial, Moreno se opõe ao modelo e se posiciona enquanto um dos representantes da geração de intelectuais Mapuche, comprometendo-se com um projeto político que faz do campo intelectual uma ferramenta de colaboração com as lutas e anseios de seu povo. 
No artigo ¿Soy America Latina? A relação dos brasileiros com a identidade latino-americana, Ricardo Bruno Boff e Aline de Souza Moreira abordam a pouca identificação dos brasileiros com a ideia de latino-americanidade, verificada em pesquisa onde apenas 4\% dos entrevistados no país se consideram latino-americanos, número inferior ao de todos os outros países do continente. Os autores discutem o contexto histórico da interação entre Brasil e América Latina a partir da colonização, passando pelas iniciativas de integração regional dos governos no século XX e a própria peculiaridade de ser o único da sub-região a falar o idioma português. A despeito das inúmeras dimensões comuns da cultura, na história e na geografia e embora existam tentativas de aproximação econômicas e políticas, poucos efeitos foram observados no aspecto da identidade do brasileiro com a América Latina.

Retornando ao Brasil, Marcos Vinícius Lustosa Queiroz e Rodrigo Portela Gomes apresentam Clóvis Moura e a teoria crítica do direito: apontamentos conceituais a partir do pensamento negro marxista, em que enumeram momentos importantes no resgate das memórias e contribuições elaboradas pela política cultural da margem brasileira do Atlântico negro, como os Congressos do Negro Brasileiro na década de 1940, o Teatro Experimental do Negro e o movimento negro das décadas de 1970 e 1980 e discutem autores que escreveram sobre a compreensão da história e da sociedade brasileira na reação com colonialismo, escravidão, racismo e diáspora africana, São destaques autores como Abdias do Nascimento, Guerreiro Ramos, Beatriz Nascimento, Eduardo de Oliveira e Oliveira e Lélia González, que subvertem as narrativas hegemônicas sobre a identidade nacional fazendo rupturas conceituais acerca do que é o Brasil, ou ser brasileiro.

O livro encerra-se na região Norte, com Andreici Marcela Araújo de Oliveira, no texto Povos indigenas, desenvolvimento e colonialismo na Amazônia Brasileira que problematiza como os povos chamados indígenas na Amazônia constroem sua relação com o colonizador, os empresários das grandes obras e o Estado brasileiro. Também busca compreender as lutas no movimento indígena que tem ocupado espaços institucionais a fim de conseguir manter seus territórios. A autora apresenta o debate sobre desenvolvimento e modernidade como algo imposto a partir de uma realidade que não condiz com os moradores da região e expõe as contradições dos projetos de desenvolvimento e as políticas para a região que favorecem o capital internacional na mesma proporção que enfraquecem a realidade social local, empobrecem a população, aumentam o desmatamento e ameaçam os povos indígenas, que reagem com o surgimento de um movimento que expressa processos organizacionais constituídos por uma nova geração de militantes e líderes que tiveram acesso à educação formal conquistada por este mesmo movimento. A despeito das diferenças, os povos se encontram no desejo de unicidade e luta para se defender das ameaças ao território e de novas formas de extermínio - do massacre físico ao da caneta - tentando inverter o espiral da invisibilidade nos discursos hegemônicos ao tentar buscar espaço e participação nas discussões políticas educacionais, territoriais e de saúde.

Ao compreender o processo histórico de cada país a partir dos estudiosos que elaboraram o entendimento acerca da formação sociológica destes, podemos perceber um universo epistemológico diverso e coerente para elaboração de uma inversão do olhar, onde o sul é visto como centralidade de suas multiculturas, seus diversos povos e a pluralidade de suas lutas, decodificando assim uma série de elementos formativos que nos identifica mais do que nos afasta. É uma espécie de cardápio de epistemologias essencial para quem caminha seus primeiros passos nos estudos sobre a decolonialidade latino-americana, pois nos permite um panorama amplo da ecologia de saberes e pode fornecer subsídios para aprofundamento dos 
estudos de autores críticos, que se encontram no polo de oposição em relação à visão cientificista clássica e hegemônica de matriz europeia. 